\title{
Preparation of iron-based ultrafine powders by a chemical method Kargin J. ${ }^{1}$, Mukhambetov D. ${ }^{2}$, Maucynbaev S. ${ }^{3}$ \\ Получение ультрадисперсных порошков на основе железа химическим методом Каргин Д. Б. ${ }^{1}$, Мухамбетов Д. Г. ${ }^{2}$, Маусымбаев С. С. ${ }^{3}$
}

\author{
${ }^{I}$ Каргин Дюжумат Бейсембекович / Kargin Jитаt - кандидат физико-математических наук, доцент, \\ кафедра физики твердого тела, \\ Евразийский рачиональный университет им. Л. Н. Гумилева, г. Астана; \\ ${ }^{2}$ Мухамбетов Даут Галимжанович / Mukhambetov Daut - доктор физико-математических наук, профессор кафедры, \\ кафедра информационных систем, \\ Алматинская академия экономики и статистики, г. Алма; \\ ${ }^{3}$ Maусымбаев Серикбай Салимбекович / Mausynbaev Serikbay - доктор педагогических наук, заведующий кафедрой \\ кафедра физики, \\ Государственньй университет им. Шакарима, г. Семей, Республика Казахстан
}

\begin{abstract}
Аннотация: данная статья посвящена обзору применения химического метода синтеза нанопорошков на основе железа путем осаждения (соосаждения). Рассмотрена общая структура этого метода, представляющая совокупность последовательных стадий растворения оксидов железа в кислотном растворе с образованием хлоридов железа, гидролиз хлоридов железа с выпадением осадка гидрооксида железа, термическое разложение гидрооксида железа с образованием осадка гематита, восстановление гематита водородом до наночастии железа. Приведены примеры использования химического метода осаждения для очистки горячекатаных полос от прокатной окалинь и синтеза магнитных нанокристаллитов маггемита.
\end{abstract}

Abstract: this article reviews the use of chemical method of synthesis of nanopowders based on iron by precipitation (coprecipitation). The general structure of this method representing the set of consecutive stages of dissolution of iron oxides in an acid solution to form iron chloride, iron chloride hydrolysis to precipitate iron hydroxide, iron hydroxide is thermally decomposed to form a precipitate hematite, hematite hydrogen recovery to iron nanoparticles. Examples of the use of chemical vapor deposition method for cleaning hot-rolled strip from the mill scale and the synthesis of maghemite nanocrystals.

Keywords: chemical precipitation method, ultrafine powders based on iron, synthesis of nanoparticles of maghemite, mill scale.

Ключевые слова: химический метод осаждения, ультрадисперсные порошки на основе железа, синтез наночастиц маггемита, прокатная окалина.

Введение. Одним из наиболее перспективных классов современных материалов являются ультрадисперсные (нано-) системы и созданные на их основе новые функциональные материалы с заданными свойствами. В последние годы большое внимание уделяется получению и исследованию ультрадисперсных порошков (УДП) на основе металлов. Среди них особое место занимают ультрадисперсные порошки железа и его окислов, благодаря уникальным свойствам этого металла.

Железо относится к металлам переходных групп с недостроенной d-электронной оболочкой и имеет четыре степени окисления $(0,+\mathrm{II}$, III, VI), что определяет особенности его взаимодействия с другими элементами. Для железа характерен полиморфизм: оно имеет четыре кристаллических модификаций ( $\alpha$-Fe, $\beta$ $\mathrm{Fe}, \gamma$ - Fe, $\delta$-Fe), определяющие широкий спектр функциональных возможностей синтезируемых на его основе материалов.

Исследования в области нанотехнологий выявили целый ряд новых свойств наноразмерных систем на основе железа и его соединений с другими элементами. К таким свойствам относятся магнитные, электрические, оптические, адсорбционные, каталитические, геохимические, биологические и другие. Вместе с тем широкое внедрение наноматериалов сдерживается порой технической сложностью, значительной стоимостью и низкой производительностью технологического оборудования, жесткими требованиями к исходному сырью и другими факторами, делающими промышленное производство УдП экономически неоправданным. Поэтому разработка новых, модернизация существующих и обоснованный выбор наиболее оптимальных методов получения нанопорошков является актуальной проблемой.

Получение УДП железа из железорудных материалов химическим методом осаждения. Существуют различные методы получения тонкодисперсных материалов, которые по типу диспергирующего воздействия делятся на механические, физические, химические и биологические. Среди них наибольшее распространение в настоящее время получили химические методы, для которых характерны сравнительная простота 
технологического цикла, доступность исходных материалов, достаточно высокая производительность в сочетании с хорошим качеством выпускаемой продукции. Так, методы химического осаждения заключаются в совместном осаждении (соосаждении) компонентов сырья из раствора в виде нерастворимых солей или гидроксидов.

В качестве базовой технологической схемы получения УДП порошков железа рассмотрим принципиальную структуру химического метода осаждения, в основу которого положен золь-гель процесс формирования наночастиц [1,2].

Исходным сырьем может служить железорудный концентрат, прокатная окалина или иной материал, содержащий железо и его оксиды.

Начальной стадией технологического процесса является отделение железной составляющей исходного сырья от примесей путем растворения железа в кислоте [2 с.11]. В этом случае, ионы железа переходят в раствор, а шлак, состоящий из нерастворимых примесей, останется в осадке. На этой стадии, если рассматривать общий случай, могут протекать реакции взаимодействия основных составляющих сырья (гематита, магнетита, вюстита и железа) с кислотой, например, соляной, по следующим схемам:

$$
\begin{gathered}
\mathrm{Fe}_{2} \mathrm{O}_{3}+6 \mathrm{HCl}=2 \mathrm{FeCl}_{3}+3 \mathrm{H}_{2} \mathrm{O} ; \\
\mathrm{Fe}_{3} \mathrm{O}_{4}+8 \mathrm{HCl}=2 \mathrm{FeCl}_{3}+\mathrm{FeCl}_{2}+4 \mathrm{H}_{2} \mathrm{O} ; \\
\mathrm{FeO}+2 \mathrm{HCl}=\mathrm{FeCl}_{2}+\mathrm{H}_{2} \mathrm{O} ; \\
\mathrm{Fe}+2 \mathrm{HCl}=2 \mathrm{FeCl}_{2}+\mathrm{H}_{2} .
\end{gathered}
$$

Как видно из реакций 3 и 4 ион $\mathrm{Fe}+2$ может находиться не в высшей степени окисления, но при осаждении гидроксида железа из $\mathrm{FeCl}_{2}$ возникают дополнительные реакции, при которых ионы железа переходят в трёхвалентное состояние.

Следующей стадией является получение кислородсодержащих соединений железа путем взаимодействия $\mathrm{FeCl}_{3}$ с раствором щелочи $\mathrm{NaOH}$, в результате которого продукт реакции - гидроксид железа FеООН выпадает в осадок согласно реакции:

$$
\mathrm{FeCl}_{3}+3 \mathrm{NaOH}=\mathrm{FeOOH} \downarrow+3 \mathrm{NaCl}+\mathrm{H}_{2} \mathrm{O} .
$$

Значение РН реакционной среды подбирается экспериментально в пределах 7,5-12 и поддерживается постоянным. Осадок гидрооксида железа фильтруется и тщательно промывается до полной отмывки Na+ и Cl-. Далее образцы сушатся при комнатной или более высоких температурах $\left(\approx 120^{0} \mathrm{C}\right)$.

В ряде случаев с целью повышения дисперсности порошков осаждение проводят с применением поверхностно-активного вещества (ПАВ), в качестве которого , например в работе [3, с.158] использовали этиловый спирт $\left(\mathrm{C}_{2} \mathrm{H}_{5} \mathrm{OH}\right)$ или додецилсульфат натрия $\left(\mathrm{Cl}_{2} \mathrm{H}_{25} \mathrm{NaO}_{4} \mathrm{~S}\right)$. Роль ПАВ заключается в том, что его молекулы адсорбируясь на поверхности свежеобразовавшихся зародышей гидрооксида, препятствуя их агломерации и замедляя, тем самым, их рост. Без добавления ПАВ удельная поверхность (Sуд) прекурсоровгидроксидов железа составила $38 \mathrm{~m}^{3} / \Gamma$, а в присутствии $0,1 \% \mathrm{C}_{12} \mathrm{H}_{25} \mathrm{NaO}_{4} \mathrm{~S}$ возросла до $182 \mathrm{~m}^{3} / \Gamma$. Соответственно, средние размеры частиц гидроксидов, рассчитанные по значениям Ауд, снизились под влиянием ПАВ от 20 нм до 8 нм [3, с.159].

Далее проводится металлизация кислородсодержащих соединений железа, которая заключается в удалении воды на стадиях дегидратации и восстановления соответствующих оксидов (или гидроксидов) до металлов. Эти процессы оказывают основное влияние на формирование дисперсности и структуры порошковых продуктов.

Дегидратация осажденных и высушенных образцов проводится в два этапа в пределах температур 20$450{ }^{0} \mathrm{C}$. На первом этапе при температурах в промежутке 20-120 0С осуществляется удаление адсорбированной воды, второй этап приводит к удалению структурной воды по реакции:

$$
2 \mathrm{FeOOH}=\mathrm{Fe}_{2} \mathrm{O}_{3}+\mathrm{H}_{2} \mathrm{O} .
$$

В соответствии с расчетами пиролиз гидрооксида а-FeOOH по реакции (6) начинается со $120^{\circ} \mathrm{C}$ и сопровождается параллельным процессом удаления остатков адсорбированной воды. Выпавший в осадок продукт реакции (6) по данным рентгенофазовых измерени представляет собой гематит.

На следующей стадии проводится восстановление кислородсодержащих соединений железа в атмосфере водорода в неизотермических условиях последовательного нагрева в промежутке температур от $20^{\circ} \mathrm{C}$ до $\approx 500^{\circ} \mathrm{C}$. Он проходит в четыре этапа. Первые два этапа приводят к дегидратации гидроксида железа, рассмотренной ранее. На третьем этапе продолжается отделение структурной воды от гидроксида по реакции (6) и образовавшийся при этом гематит восстанавливается до магнетика:

$$
\mathrm{Fe}_{2} \mathrm{O}_{3}+\mathrm{H}_{2} \rightarrow 2 \mathrm{Fe}_{3} \mathrm{O}_{4}+\mathrm{H}_{2} \mathrm{O}
$$


На четвертом этапе, начиная примерно с $350^{\circ} \mathrm{C}$, протекают реакции восстановления магнетита до дисперсного железа:

$$
\mathrm{Fe}_{3} \mathrm{O}_{4}+4 \mathrm{H}_{2} \rightarrow 3 \mathrm{Fe}+4 \mathrm{H}_{2} \mathrm{O}
$$

По результатам рентгенофазового анализа все восстановленные образцы представляли собой порошок $\alpha$ Fe. Морфологические исследования продуктов восстановления показали, что они относятся к классу нанопорошков. Так, после восстановления при $400^{\circ} \mathrm{C}$ средние размеры частиц железа, рассчитанные по данным измерения удельной поверхности (Dcp), электронной микроскопии (Dэл) и рентгеновского анализа (DHKL), составили: Dcp $=60$ нм, Dэл $=76$ нм, DHKL $=36 \mathrm{Hм}$, а в случае применения ПАВ $0,1 \% \mathrm{C}_{12} \mathrm{H}_{25} \mathrm{NaO}_{4} \mathrm{~S}$ в процессе осаждения прекурсоров-гидрооксидов, средние размеры восстановленных наночастиц железа уменьшились примерно вдвое и составили, соответственно, 25 нм, 35 нм и 19 нм [3, с.163]. Анализ показал, размер частиц Dэл складывается в среднем из двух размеров областей когерентного рассеяния DHKL.

Восстановленный тонкодисперсный порошок железа пассивируют и отправляют потребителю или же используют для последующей обработки.

Получение оксидных порошков на основе железа из прокатной окалины. Рассмотренные выше процессы, сопровождаемые реакциями (1-6), используются в условиях металлургического производства для очистки стальных полос после горячей прокатки от прокатной окалины [4]. Окалина на поверхности подката состоит из вюстита, магнетита и гематита. Непосредственно к металлу примыкает слой вюстита (до половины от общей толщины окалины), наружный слой представляет собой гематит (до $10 \%$ толщины, между ними располагается слой магнетита. Самым плотным является слой гематит, который и создает основную трудность в освобождении горячекатаных полос от окалины.

Среди промышленных способов удаления окалины с поверхности полосы наиболее часто применяется химический метод, заключающийся в растворении (травлении) оксидов железа раствором соляной кислоты. Эти процессы описываются химическими уравнениями реакций (1-4). Образующий при взаимодействии НСl с окалиной хлористое железо хорошо растворяется в воде, что дает возможность полной регенерации всех сточных растворов, свободных от нерастворимых осадков. Шлам, который образуется из остатков окалины, выпадает в осадок и удаляется при промывании ванн и поверхности полос.

Далее отработанный травильный раствор поступает реактор - стальную башню, отапливаемую газовыми горелками, где он разогревается до $\mathrm{T}=600^{\circ} \mathrm{C}$. При этом растворенный в травильном растворе хлорид железа $\mathrm{FeCl} 2$ распадается на тонкодисперсный гематит $\mathrm{Fe}_{2} \mathrm{O}_{3}$ и газообразный $\mathrm{HCl}$ согласно реакции:

$$
4 \mathrm{FeCl}_{2}+4 \mathrm{H}_{2} \mathrm{O}+\mathrm{O}_{2}=2 \mathrm{Fe}_{2} \mathrm{O}_{3}+8 \mathrm{HCl} .
$$

Порошкообразный гематит отделяется в циклонах от отходящих газов и ссыпается в нижнюю часть реактора, и оттуда поступает в бункер. Оксид железа отгружается в виде порошка, либо в виде гранул. На металлургическом заводе он обычно используется непосредственно на аглофабриках.

Оксидный порошок, полученный из прокатной окалины, является ценным материалом для использования в различных отраслях науки и народного хозяйства. Как было показано нами в работе [5] прокатная окалина нелегированных сталей является наиболее чистой по примесям и она может быть использована для получения тонкодисперсных порошков железа или его оксидов. Выявленные закономерности роста оксидной пленки и перехода ее в окалину на поверхности нелегированных сталей могут служить научной основой для разработки нового способа получения наночастиц оксида железа путем поверхностного оксидирования таких сталей $[5,6]$.

Синтез магнитных наночастиц методом соосаждения. В последние годы большой интерес представляет использование магнитных наночастиц железа $\gamma$ - $\mathrm{Fe}_{2} \mathrm{O}_{3}$, благодаря проявлению у них суперпарамагнитных свойств при комнатной температуре. В ряде работ [7,8 ] было показано, что наиболее приемлемым для получения нанопорошков маггемита $\gamma-\mathrm{Fe}_{2} \mathrm{O}_{3}$ является химический метод осаждения. Так, в работе [8] магнитные нанокристаллиты однофазного (МНК) маггемита были получены с помощью метода соосаждения по следующей процедуре. Первоначально, наночастицы прекурсора магнетита $\left(\mathrm{Fe}_{3} \mathrm{O}_{4}\right)$, были получены из хлорида железа II и хлорид железа III в водном растворе щелочной среды без поверхностноактивных веществ или органических растворителей. Далее с помощью хлористоводородной кислоты осуществлялось окисление $\mathrm{Fe}_{3} \mathrm{O}_{4}$ в $\gamma$ - $\mathrm{Fe}_{2} \mathrm{O}_{3}$. Высушенный при температуре около $40{ }^{\circ} \mathrm{C}$ порошок красноватокоричневого цвета обладал всеми характеристиками, свойственными МНК маггемита. Средние размеры частиц, оцененные по уширению рентгеновских линий и данным просвечивающей электронной микроскопии составили 6,4 \pm 1 нм и 6,8 $\pm 0,1$ нм, соответственно. Средний размер магнитных доменов, вычисленный из магнитных измерений, был равен 6,5 нм, что подтверждает, что свидетельствует об однодоменности синтезированного маггемита. Значение константы кристаллографической анизотропии составило Кэфф = 1,6 × 104 Дж / м3. Полученные результаты позволили констатировать авторам [8, с. 120], 
что химический метод путем совместного осаждения прекурсоров является надежным методом синтеза магнитных нанокристаллитов маггемита.

Заключение. Проведен обзор применения химического метода синтеза напорошков на основе железа путем осаждения (соосаждения). На примере получения ультрадисперсных порошков железа из железорудного концентрата рассмотрена общая структура этого метода, представляющая совокупность последовательных стадий:

- растворение оксидов железа в кислотном растворе с образованием хлоридов железа,

- гидролиз хлоридов железа с выпадением осадка гидрооксида железа,

- термическое разложение гидрооксида железа с образованием осадка гематита,

- восстановление гематита водородом до наночастиц железа.

Показано, совместное осаждение прекурсоров является надежным методом синтеза магнитных нанокристаллитов маггемита.

Работа выполнена в рамках научного гранта «Разработка технологии получения нанопорошков железа методом поверхностной оксидации нелегированной стали» Комитета науки Министерства образования и науки Республики Казахстан по договору №45 от 12 февраля 2015 года.

\section{Лumepamypa}

1. Xingzhong Guo, Qilong Zhang, Xingeng Ding, Qianhong Shen, Chunchun Wu, Lingjie Zhang, Hui Yang. Synthesis and application of several sol-gel-derived materials via sol-gel process combining with other technologies: a review//Journal of Sol-Gel Science and Technology. Published online: 16 January 2016, pp. 1-31. URL: http://link.springer.com/article/10.1007/s10971-015-3935-6\#page-1 (дата обращения: 10.05.2016).

2. Конюхов Ю. В., Рыжонков Д. И., Левина В. В., Дзидзигури Э. Л. Получение нанопорошков железа из железорудного материала//Известия высших учебных заведений. Черная металлургия, 2005, № 3, с. 11-15.

3. Конюхов Ю. В., Левина В. В., Рыжонков Д. И., Пузик И. И. Свойства наноразмерных порошков железа, полученных химико-металлургическим методом с применением поверхностно-активных веществ//Российские нанотехнологии, 2008, т. 3, № 5-6, с. 158-163.

4. Очистка горячекатаных полос от окалины. URL: http://dlja-mashinostroitelja.info/2012/01/2-ochistkagorjachekatanyh-polos-podkata-ot/ (дата обращения: 17.05.2016).

5. Каргин Д. Б., Мухамбетов Д. Г., Чалая О. В. Научные основы получения нанопорошков на основе железа путем поверхностной оксидации нелегированной стали // Вестник ЕНУ им. Л. Н. Гумилева, Серия естественно-технических наук, 2015, № 3, с.72-76.

6. Mukhambetov D. G., Chalaya O. V. On the mechanism of self-deceleration of the thin oxide film growth // Journal of Vacuum Science and Technology. A. (USA), 2002, Vol. 20, No 3, pp. 839-842.

7. Mousa Nazari, Nahid Ghasemi, Heydar Maddah et al. Synthesis and characterization of maghemite nanopowders by chemical precipitation method// Journal of Nanostructure in Chemistry, 2014, No 6, pp. 1-5.

8. Juan Adrián Ramos Guivar, Arturo Isaías Martínez, Ana Osorio Anaya et all. Structural and Magnetic Properties of Monophasic Maghemite $\left(\gamma-\mathrm{Fe}_{2} \mathrm{O}_{3}\right)$ Nanocrystalline Powder//Advances in Nanoparticles, 2014, Vol.3, No 3, pp. 114-121. 